\title{
Loss of rapid phonological recoding in reading Hanja, the logographic script of Korean
}

\author{
JEESUN KIM \\ Yeungnam University, Taegu, Korea \\ and University of Melbourne, Parkville, Australia \\ and \\ CHRIS DAVIS \\ University of Melbourne, Parkville, Australia
}

\begin{abstract}
The role that recent experience has in the processing of Korean Hanja characters was investigated in two masked priming experiments. Two groups of Korean native speakers that differed in their recent exposure to Hanja were asked to name single Hanja characters (targets) that were immediately preceded by masked presentations of the same characters (repetition priming), Hanja characters that were homophones of the target (homophone priming), or unrelated characters (baseline). The results showed that the group that had been less recently exposed made more errors and were slower than the group that had been the more recently exposed. Furthermore, there was no character homophone priming for the less recently exposed group, although they did show a robust repetition priming effect. On the other hand, the more recently exposed group showed both strong character repetition and homophone priming effects. We suggest that regular exposure to characters supports their rapid and automatic processing. It is argued that the different patterns of priming for the two groups were due to how rapidly the orthographic and phonological information of the prime could be resolved.
\end{abstract}

The development of automaticity of processing is considered to be the hallmark of the development of fluent reading (see, e.g., La Berge \& Samuels, 1974). To be a skilled reader, it is argued, the processing of letters, syllables, and words must be overlearned to a point of automatic responding so that the learner can attend to higher level comprehension and reasoning. The conception of automaticity in word recognition has largely been framed in terms of the developing reader, based as it is on the principle that, through practice, tasks become easier and require less attention. That is, automaticity of processing can be regarded in terms of the development of a rapid processing that is not reliant on conscious control. Experimental investigations have also adopted a developmental approach, with recent studies attempting to gauge the degree of automaticity of the word recognition process in developing readers (see Castles, Davis, \& Letcher, 1999; Davis, Castles, \& Iakovidis, 1998; Praterelli, Perry, \& Galloway, 1994). Less attention has been given to the issue of the maintenance of such automatic processing over time.

In this paper, we are concerned with the possible loss of automatic processing in adult readers (for present purposes, we are characterizing automaticity in terms of rapid

This work was supported by a postdoctoral fellowship to the first author from the Korean Ministry of Science and Technology under the Brain Science Research Program. Correspondence concerning this article should be addressed to J. Kim, Department of Psychology, University of Melbourne, Parkville, Victoria 3010,Australia (e-mail: jeesun@ unimelb.edu.au). and obligatory processing). There is, of course, a good reason why this topic has received little attention, since typically, once a person can read, he/she goes on reading throughout his/her lifetime. Indeed, in alphabetic languages, a reader does not even have to read many words to practice the entire set of letters and many frequent letter clusters. However, this is not the case for nonalphabetic systems, for which specific characters may not be encountered very often at all. Furthermore, the pronunciation of characters has to be learned by rote, since, in most cases, characters cannot be pronounced by recourse to rules or by subcharacter components (radicals). This differs from alphabets and suggests the importance of frequent exposure to characters for automatic processing in naming (see Tan, Hoosain, \& Peng, 1995).

This possibility of infrequent exposure to particular characters is magnified in the Korean writing system, because it uses both an alphabetic (Hangul) and a characterbased (Hanja) script. In addition, although these scripts are used within the same text, Hangul (the alphabetic script) is used more often than Hanja. Moreover, Hanja is not always used. Typically, it might be used in professional texts and only in certain newspapers. Thus, although at one stage in their lives educated Koreans will know and practice Hanja (it is taught throughout secondary school), the reinforcement of this learning (by reading) may be extremely variable. Indeed, for adults studying outside Korea, exposure to Hanja may be very limited, since the texts they study are probably not in Korean and local Korean newspapers often do not use Hanja to any extent. 
In this study, the process of reading Hanja is investigated by contrasting the performance of two groups of Koreans: University students studying in Seoul, Korea were compared with students studying in Sydney, Australia. Given that the process of reading involves the operation of a wide and complex mix of processes and strategies, experimental ingenuity is required to try to partition out those factors that may be concerned with language processing from those more general processes involved in motivation, attention, memory, and the like. Further ingenuity is required to separate out rapid and automatic processing (where it exists) from that which is more controlled and, to some degree, slower.

The approach that we have adopted is to test language processing using a procedure that involves an implicit, rather than an explicit, measure of processing. That is, the measure we employ does not require that the participant be aware of what is actually being tested. The procedure we will use is well established in the experimental literature and is based on the phenomenon of priming. The term priming has had broad application; we use it here to describe a situation in which a facilitation in performance for one stimulus (the target) occurs given a previous encounter with another (the prime). Priming effects have been shown to occur over a range of primetarget relationships: In repetition priming, the prime and the target stimuli are the same (Scarborough, Cortese, \& Scarborough, 1977); in semantic and associative priming, there is either a meaning-based or an experiential link between the prime and the target (Meyer \& Schvaneveldt, 1971); and in form priming, the prime and the target share properties of form-that is, an orthographic or phonological relationship (Hillinger, 1980). Effects of this kind have been used to make inferences about the properties of the information-processing systems underlying word recognition performance.

The type of priming used in the studies above may be inappropriate for the present research endeavor. Typically, such studies have involved long-term priming. In this method, the prime stimulus is clearly displayed and may precede the target by several seconds or even minutes. In such a situation, the response to the target may not be facilitated by the immediate processing of the prime but, rather, by recovering the episodic record of that processing. In this study, we want a technique that is more sensitive to the on-line processing of the prime, one that acts to constrain the type of processing that may contribute to a response and, in this way, help determine whether information about the prime can be extracted rapidly and automatically. An approach that combines the indirect priming method with a temporal restriction on the availability of the prime is masked priming (see Ferrand \& Grainger, 1992; Forster \& Davis, 1984; Forster, Davis, Schoknecht, \& Carter, 1987; Grainger \& Ferrand, 1994). In this method, a briefly displayed prime immediately precedes the target and is itself preceded by a series of hash marks that acts as a forward visual mask. The initial forward mask and the target (which acts as a backward mask) are clearly visible and are displayed for a fixed period of $500 \mathrm{msec}$. The prime is displayed briefly (usually, between 40 and $60 \mathrm{msec}$ ), and the combined action of the forward and backward masks makes the prime unavailable for conscious report.

The present experiments used masked priming to test for a loss in the rapid and automatic processing of written information. The idea is that the occurrence of priming attests to both the rapid and the mandatory processing of the prime. That is, for priming to occur, the prime must have been processed rapidly enough to affect the target decision; given that participants are not aware of the presence of the prime, we assume that the extraction of this information is nonintentional. The experiments use Hanja homophonic primes and targets to examine whether a participant group that has less current exposure to Hanja shows less priming than does one that has more recent experience of Hanja. There are several reasons for using homophone priming as an index of level of automaticity of processing. First, the pronunciation of characters has to be learned by rote, and thus, the speed of its recruitment may be influenced by the frequency of use. Second, for a homophone effect to be shown, the prime character must be processed to a considerable extent, since Hanja characters have no sublexical orthographic constituents that reliably indicate whole character pronunciation. Third, use of Hanja homophones offers a convenient way of dissociating the physical aspects of the prime and the target, while allowing for their phonological identity. That is, as is the case in Chinese, many syllables can be represented by more than one Hanja character (e.g., 丹, 断, 單 are all pronounced /dan/). Note that this is not the case for repeated primes and targets since, although the size of primes and targets differ (see the Method section), their forms do not.

In Experiment 1, homophone priming was assessed by using Hanja primes and targets for participants who, by virtue of living in Seoul, had day-to-day experience with Hanja. Experiment 2 used the same materials as those in Experiment 1, but with a group of graduate and postgraduate students in Sydney who were not exposed to Hanja on a regular basis. To ensure optimal conditions for demonstrating a homophone effect, naming was used as the response measure, since this task appears to be more sensitive to such effects (see, e.g., Lukatela \& Turvey, 1994; Shen \& Forster, 1999).

The results of other masked priming experiments provide a guide as to what might be expected from this first experiment. There have been a number of demonstrations of masked homophonic priming with alphabetic scripts when naming is the response measure (e.g., Kim, 1998; Lukatela \& Turvey, 1994). Moreover, in a recent masked priming study in Chinese, Shen and Forster (1999) demonstrated robust priming of the pronunciation of Chinese character targets when they were preceded by homophonic characters. On the basis of these findings, then, it is expected that there should be a reliable masked homophonic priming effect. This result would indicate that participants who are regularly exposed to Hanja characters can process a rapidly dis- 
Table 1

Mean Naming Latencies (RTs, in Milliseconds) and Error Rates (in Percentages) for Hanja Targets as a Function of Prime Type (in Hanja) for Participants Tested in Seoul

\begin{tabular}{lcccc}
\hline Prime Type & Example & RT & Size of Effect & \%ER \\
\hline Repetition & 哭- 哭 & 778 & +49 & 7.5 \\
Homophone & 曲 - 哭 & 778 & +49 & 5.3 \\
Unrelated & 月 - 哭 & 827 & & 7.2 \\
\hline
\end{tabular}

played character (of which they are unaware) to a sufficient degree to facilitate the naming of an immediately following homophonic target.

\section{EXPERIMENT 1 Homophone Priming in a Frequent Hanja Experience Group}

\section{Method}

Participants. Thirty-six Korean undergraduate and postgraduate students studying at Korea University (Seoul) participated in the experiment. The ages of the participants ranged from 24 to 36 years.

Materials. Thirty monosyllabic Hanja target characters were used for naming. Each target was preceded by one of three types of prime: repetition, homophone in Hanja, and unrelated. For this purpose, 30 pairs of homophonic characters in Hanja were chosen for the primes and the targets. Ten characters that were nonrelevant to the target word (they had no semantic or phonological connection to the target) were also chosen for the unrelated primes. Characters were selected on the basis of the first author's intuition that they were commonly used and relatively simple in terms of character complexity; in general, the simpler of the homophonic pair was chosen for the prime. In this and the following masked priming experiment, primes (including repetition primes) were presented in a smaller font (i.e., the horizontal and vertical length for each character was $5 \mathrm{~mm}$ ), and targets were presented in a large font (the horizontal and vertical length for each syllable was $10 \mathrm{~mm}$ ), using Hangul Word Processor Version 1.5. Three sets of materials were constructed so that each target appeared once in each set, but each time in a different condition. Different groups of participants were used for each set of materials.

Procedure. Each trial consisted of the following display sequence. Half a second after the previous trial ended, a forward mask, consisting of a row of hash marks (e.g., \#\#\#\#), appeared in the center of the screen for $500 \mathrm{msec}$. This mask was followed by the prime in the small font, which remained on the screen for three refresh cycles (the refresh time for the video card was $14.2 \mathrm{msec})^{1}$. The prime was followed by the large-font target, which remained on the screen for a further $500 \mathrm{msec}$. The initial hash mask was matched in length to the prime to ensure that the entire prime was masked.

The participants were randomly allocated to one of the three versions of the experiment. They were told that a row of hash marks would appear as a ready signal; then a word would follow that they should say aloud as quickly and as accurately as possible. The participants were not informed about the existence of the small Hanja prime. The participant's vocal response triggered the voice-switch, which stopped the computer's millisecond timer. Both latency and accuracy feedback were displayed to the participant after each trial.

Data treatment. If a participant failed to pronounce an item at all or the trial was disrupted (e.g., by an extraneous noise), the data from that item were excluded. In this, as in the subsequent experiment, reaction times more than two standard deviation units above or below the mean for that participant in all conditions were trimmed to the appropriate cutoff value. Lower and upper absolute cutoff limits were set at 200 and 2,500 msec. On the basis of other naming studies with Hanja (Kim, 1998, using populations similar to that which will be used in Experiment 2), an error cutoff criterion of $23 \%$ was selected. This figure was chosen as a compromise between maximizing usable trials and minimizing the number of individuals that would need to be run.

\section{Results and Discussion}

Naming response times and error rates in percentages for each of the prime conditions are shown in Table 1. As can be seen, those targets preceded by repeated and by homophone primes were processed faster than were those targets preceded by unrelated primes.

The overall analysis of the latency data showed a significant difference among the different types of prime $\left[F_{1}(2,66)=8.37, p<.01 ; F_{2}(2,54)=11.31, p<.001\right]$. There was no difference in error rate as a function of prime type (both $F \mathrm{~s}<1$ ). In terms of response speed, the repetition primes significantly facilitated the naming response, in comparison with the unrelated primes $\left[F_{1}(1,33)\right.$ $\left.=12.74, p<.001 ; F_{2}(1,27)=14.937, p<.001\right]$; there was no error effect (both $F_{\mathrm{S}}<1$ ). There was a significant homophone priming effect in the latency data $\left[F_{1}(1,33)\right.$ $\left.=9.11, p<.01 ; F_{2}(1,27)=17.50, p<.001\right]$, although there was no effect for errors $\left[F_{1}(1,33)=1.15, p>.05\right.$; $\left.F_{2}<1\right]$. It is clear from the results of Experiment 1 that the participants showed a strong homophone priming effect, one equal in size to the repetition priming effect.

How do the present results fit with those of other experiments? The homophone priming results from the skilled Hanja readers are consistent with those of other studies (e.g., Lukatela \& Turvey, 1994; Tzelgov, Henik, Sneg, \& Baruch, 1996; Van Orden, 1987; Ziegler, Van Orden, \& Jacobs, 1997) that have shown that activation of phonology is mandatory (occurring even when it "hurts" performance in the task). The results also are consistent with those of Shen and Forster (1999), who found a masked homophone priming effect for the naming of Chinese characters.

Having demonstrated a homophone priming effect in Hanja with a participant group regularly exposed to this script, the question remained as to what would happen with speakers who had learned Hanja but had not been exposed to it on a regular basis for several years. Given that the crucial factor in producing a homophone priming effect may be how quickly a Hanja character can be decoded to its phonological form, it was expected that, for this group, a reduced homophone priming would be found.

\section{EXPERIMENT 2 Homophone Priming in an Infrequent Hanja Experience Group}

\section{Method}

Participants. Thirty-six Korean undergraduate and postgraduate students studying at the University of New South Wales participated in the experiment. The ages of the participants ranged from 27 to 38 years. They had been in Australia for an average of 3.8 years and were tested individually. Given the participants ages and educational levels, it could safely be assumed that they would have 
Table 2

Mean Naming Latencies (RTs, in Milliseconds) and Error Rates (in Percentages) for Monosyllabic Hanja Targets as a Function of Prime Type (in Hanja) for Participants Tested in Sydney

\begin{tabular}{lcccc}
\hline Prime Type & Example & RT & Size of Effect & \%ER \\
\hline Repetition & 哭- 哭 & 867 & +35 & 11.9 \\
Homophone & 曲 - 哭 & 925 & -22 & 11.3 \\
Unrelated & 月 - 哭 & 902 & & 13.6 \\
\hline
\end{tabular}

(at one stage) been able to fluently read all the Hanja materials in the experiment. Fifty-five people were needed to obtain 36 who met the criterion of less than $23 \%$ errors.

Materials. The same materials as those Experiment 1 were used in the present experiment.

Procedure. The same procedure was used as that in Experiment 1.

\section{Results and Discussion}

Reaction times and error rates for each experimental condition are provided in Table 2 .

The overall analysis of the latency data showed a significant difference among the different types of primes, $\left[F_{1}(2,66)=10.92, p<.001 ; F_{2}(2,54)=7.68, p<.001\right]$. There was no difference in error rate as a function of prime type (both $F_{\mathrm{S}}<1$ ). The majority of errors were disfluencies (approximately $40 \%$; i.e., hesitations, inappropriate triggering of the voice switch by lip-smacks or other noises) or participants' saying a different character name than the one displayed (45\%; typically a formbased confusion). The repetition primes significantly facilitated the naming response, in comparison with the unrelated primes $\left[F_{1}(1,33)=8.46, p<.001 ; F_{2}(1,27)=\right.$ $5.47, p<.01]$. The homophone primes appeared to have caused delay in processing the targets, but not significantly so $\left[F_{1}(1,33)=2.88, p>.05 ; F_{2}(1,27)=3.09, p>\right.$ $.05]$. In order to provide some support for the hypothesis that homophone priming may be apparent only for those people who process Hanja rapidly and efficiently, a correlational analysis was conducted. Priming scores for each individual were calculated by first obtaining the latencies of each participant for each condition, relative to the average reaction time for all the participants in that particular experimental list. These list-independent scores were then used to calculate a homophone priming score by subtracting the unrelated condition from the average latency for the homophone condition for the same set of items (i.e., across experimental lists). There was a significant correlation between the size of homophone priming and the speed of response, with the faster participants showing a larger priming effect $[r=.613, p<.01]$. This correlation suggests that the fast participants may show a tendency for homophone priming, whereas the slower ones show a tendency for homophone inhibition. This can be demonstrated by selecting two groups of participants (a fast and a slow group) on the basis of a median split of their overall reaction times. The mean for the homophone priming for the fast group was $13 \mathrm{msec}$, whereas mean homophone priming for the slow group was $-59 \mathrm{msec}$. Suggestions as to how, in the slow group, a homophone prime may generate inhibition will be taken up briefly in the General Discussion section.

Having completed the analysis of the data from the second experiment, the following analyses will examine contrasts across both Experiments 1 and 2. As can be seen by comparing Tables 1 and 2, there was a considerable difference in both the speed and the accuracy of the responses of the two groups. An analysis of the overall response latencies showed that the participants in Seoul were significantly faster than those in Sydney $\left[F_{1}(1,66)\right.$ $\left.=9.13, p<.01 ; F_{2}(1,27)=21.27, p<.001\right]$. There was also a significant difference in the error data, with the Seoul group also being more accurate $\left[F_{1}(1,66)=11.08\right.$, $\left.p<.01 ; F_{2}(1,27)=4.28, p<.05\right]$.

A comparison of the size of masked priming effects shows that the amount of repetition priming is similar across the groups, whereas the pattern for homophone priming is markedly different. Analysis of repetition priming across the two groups showed that there was no difference in the size of the effect, either for response latencies (both $F_{\mathrm{S}}<1$ ) or for errors (both $F_{\mathrm{S}}<1$ ). Analysis of the homophone effect revealed that the obvious difference in the latency data was significant $\left[F_{1}(1,66)=\right.$ $\left.11.51, p<.001 ; F_{2}(1,27)=18.73 . p<.001\right]$. There was no difference for errors (both $F_{\mathrm{S}}<1$ ).

One possible reason that the Sydney group showed no phonological priming is that they were unable to process the prime in the short time that was available. Consistent with this idea is the result that the Sydney group was far slower at naming than the Seoul group (as can be seen by comparing Tables 1 and 2). Possibly then, because the Sydney participants may be relatively unfamiliar with Hanja, they may not have even registered the rapidly displayed Hanja primes (a similar argument to this was made by Nam, 1995, in order to explain why semantic priming with Hanja was difficult to find with short stimulus onset asynchronies). There is evidence in the Sydney results, however, that such a restriction in processing the data of the prime did not apply. First, there was a robust repetition priming effect. Finding repetition priming shows that participants must have processed the prime, at least to some degree. Second, there was a significant correlation between the size of the homophone effect and the overall processing speed, something that seems odd if the prime had no effect at all.

Given that the prime was processed, what needs to be explained is why there was no homophone priming. One possibility is that the absence of priming was due to the effect of the combined presentation of the prime and the target. In the masked priming procedure, because targets are displayed immediately after primes, the processing of primes and targets could become entangled. The effects of this overlap of prime and target processing would be different for repeated primes and targets, as compared with homophone primes and targets. That is, when the prime and the target are repeated, the prime and the target activate precisely the same set of orthographic and phonological representations. In the homophone case, however, the target will activate a different orthographic 
representation from that activated by the prime. In such a case, two different orthographic candidates are for a time reinforced, and this could cause a delay in deciding on a single outcome and so compromise the generation of a priming effect. The issue of how exactly the homophone priming effect is reduced and why this does not occur for skilled Hanja readers will be taken up in the General Discussion section below.

\section{GENERAL DISCUSSION}

The issue of interest in the present paper was whether lack of practice in reading characters would lead to a reduction in the recognition system's ability to rapidly generate the character's associated codes of information. The amount of practice in reading characters was varied indirectly by testing individuals who lived in Seoul or in Sydney. As a means of assessing how rapidly the information associated with a character could be activated, masked phonological priming was used. The experiments tested the degree to which target representations could be activated by rapidly displayed Hanja homophone primes that immediately preceded them. Phonological priming was chosen as an index of processing because developing the correct phonological form of a character requires substantial processing.

The results of the experiments indicated that the pattern of priming was dramatically changed as a function of continuing exposure to Hanja characters, with the Seoul group showing a robust homophone priming effect and the Sydney group showing none. In order to explain this differential effect, three things need to be considered: how Hanja characters are named, how this response is primed, and how experience in processing Hanja can change this priming effect.

A straightforward assumption is that in order to name a Hanja character, an orthographic description first needs to be developed and that, from this, a phonological representation is selected. For naming, it is the state of this phonological representation that ultimately controls the response. The response to a target character will be primed if its phonological representation has already been activated sufficiently to have reached a stable state. ${ }^{2}$ Several sorts of primes should facilitate target naming: Primes that are the same as the target (repetition priming), primes that have the same phonology as the target (homophone priming), and possibly primes that resemble the orthographic form of the target so closely that the phonological representation is activated (orthographic form priming). ${ }^{3}$

In general, then, when a character is presented, its orthographic representation is activated, and this leads to the rapid activation of its phonological representation. The activation levels of these two representations are linked, with the activation of forms consistent with the input rising until their processing is resolved; then the levels stabilize, eventually to decay. In the case of primes and targets that have different orthographic representa- tions but the same phonology (homophone primes), a phonological priming effect will result only if the processing of the target does not prevent the phonological representation of the prime from stabilizing (see Perfetti $\&$ Tan, 1998, for a similar argument).

For the skilled Hanja reader, we suggest that the process of resolving the orthographic form of the prime is rapid; hence, the target can benefit from the preactivation of any shared representations (both orthographic and phonological). For the less skilled reader, however, the process of resolving the prime is not as rapid. This does not cause a problem when the prime and the target are the same, since target processing simply takes over from the processing of the prime. However, when the orthographic forms of the prime and the target are different, the orthographic processing of the prime will be disrupted, and likewise, so will the development of its phonological code. In this case, no processing advantage will accrue to the target.

Even though there was no homophone priming for the Sydney group, there was an interesting trend in the data that suggested that those participants who were slow and error prone tended to show homophone interference, whereas those who were faster and more accurate tended to show homophone facilitation. Although the issue of homophone interference is a somewhat secondary one, it is worth pointing out that there are lexical processing models in which such an effect might occur. For instance, selective interference between homophone primes and targets (relative to the unrelated prime condition) might take place if orthographic and phonological processing is tightly interconnected, as in such models as Taft (1991, 1994), Taft and van Graan (1998), Stone and Van Orden (1994), and Stone, Vanhoy, and Van Orden (1997). Interference may arise in the following manner. We assume that in order to produce a response, an unambiguous perceptual hypothesis must be obtained. An unambiguous perceptual hypothesis comes about owing to the stabilization of feedback between orthographic and phonological interpretations. Given this, the speed of resolution of candidates is important when there are multiple inputs. That is, if the recognition system is presented with two inputs (the prime and the target) and the process of stabilizing a perceptual candidate is slow (as is supposed with the Sydney group), a response to the target will be delayed. Finally, a delay in resolving a perceptual candidate will be more likely in the case of homophonic primes and targets because the single phonological code will (for a time) reinforce both orthographic candidates. That is, in the case of homophone primes and targets, the processing of the target becomes entangled with that of the prime, and this will cause a delay in the response to the target until its processing becomes dominant.

It should be noted that the lack of a homophone priming effect from Hanja primes appears to be specific to Hanja characters and is not due to a general slowness of the Sydney group in processing Korean. That is, in a series of other experiments, Kim (1998) showed that there 
was no difference in overall response times between participants from Seoul and Sydney in the naming of Hangul (the alphabetic Korean script).

On a more general level, the result that there was no homophone priming for the group less exposed and less skilled in processing Hanja suggests that the process of word recognition is a dynamic one. That is, it appears that the processing of characters changes as a function of use/exposure, so that the rapid activation of stable orthographic and phonological codes is retarded if exposure to print is limited. This delay is particularly acute over the time course indexed by masked priming. Broadly, then, the results are compatible with word-processing models that incorporate a learning component (e.g., Plaut, McClelland, Seidenberg, \& Patterson, 1996), whereby the establishment of representations is a developmental process that takes place over an extended period of time (see Plaut \& McClelland, 2000).

\section{REFERENCES}

Castles, A., Davis, C., \& Letcher, T. (1999). Neighbourhood effects on masked form-priming in developing readers. Language \& Cognitive Processes, 14, 201-224.

Davis, C., Castles, A., \& IAKovidis, E. (1998). Masked homophone and pseudohomophone priming in children and adults. Language \& Cognitive Processes, 13, 625-651.

Ferrand, L., \& Grainger, J. (1992). Phonology and orthography in visual word recognition: Evidence from masked nonword priming. Quarterly Journal of Experimental Psychology, 45, 353-372.

Forster, K. I., \& DAVIS, C. (1984). Repetition priming and frequency attenuation in lexical access. Journal of Experimental Psychology: Learning, Memory, \& Cognition, 10, 689-698.

Forster, K. I., Davis, C., Schoknecht, C., \& Carter, R. (1987). Masked priming with graphemically related forms: Repetition or partial activation? Quarterly Journal of Experimental Psychology, 39, 211-251.

Grainger, J., \& Ferrand, L. (1994). Phonology and orthography in visual word recognition: Effects of masked homophone primes. Journal of Memory \& Language, 33, 218-233.

Hillinger, M. L. (1980). Priming effects with phonemically similar words: The encoding-bias hypothesis reconsidered. Memory \& Cognition, 8, 115-123.

KIM, J. (1998). Investigating phonological processing in visual word recognition: The use of Korean Hangul (alphabetic) and Hanja (logographic) scripts. Unpublished doctored dissertation, University of New South Wales.

KIM, J., \& DAVIS, C. (in press). Using Korean to investigate phonological priming effects without the influence of orthography. Language \& Cognitive Processes.

LaBerge, D., \& Samuels, S. J. (1974). Toward a theory of automatic information processing in reading. Cognitive Psychology, 6, 293-323.

Lukatela, G., \& Turvey, M. T. (1994). Visual lexical access is initially phonological: 1 . Evidence from phonological priming by homophones and pseudohomophones. Journal of Experimental Psychology: General, 123, 331-353.

Meyer, D. E., \& Schvaneveldt, R. W. (1971). Facilitation in recognizing pairs of words: Evidence of dependence between retrieval operations. Journal of Experimental Psychology, 90, 227-234.

NAM, K. (1995). Korean word recognition: Are different orthographies recognized differently? Unpublished doctoral dissertation. University of Texas, Austin.

Perfetti, C. A., \& TAn L. H. (1998). The time course of graphic, phonological, and semantic activation in Chinese character identification. Journal of Experimental Psychology: Learning, Memory, \& Cognition, 24, 101-118.
Plaut, D. C., \& McClelland, J. L. (2000). Comment on Page, M. (2000). Connectionist modelling in psychology: A localist manifesto. Behavioral \& Brain Sciences, 23, 4-89.

Plaut, D. C., McClelland, J. L., Seidenberg, M. S., \& Patterson, K. E. (1996). Understanding normal and disordered reading: Computational principles in quasi-regular domains. Psychological Review, 103, 56-115.

Praterelli, M. E., Perry, K. E., \& Galloway, A. M. (1994). Automatic lexical access in children: New evidence from masked repetition priming. Journal of Experimental Child Psychology, 58, 346358 .

Scarborough, D. L., Cortese, C., \& Scarborough, H. S. (1977). Frequency and repetition effects in lexical memory. Journal of Experimental Psychology: Human Perception \& Performance, 3, 1-17.

Shen, D., \& Forster, K. I. (1999). Masked phonological priming in reading: Chinese words depends on the task. Language \& Cognitive Processes, 14, 429-459.

Stone, G. O., Vanhoy, M., \& Van Orden, G. C. (1997). Perception is a two-way street: Feedforward and feedback phonology in visual word recognition. Journal of Memory \& Language, 36, 337-359.

Stone, G. O., \& Van Orden, G. C. (1994). Building a resonance framework for word recognition using design and systems principles. Journal of Experimental Psychology: Human Perception \& Performance, 20, 1248-1268.

TAFT, M. (1991). Reading and the mental lexicon. London: Erlbaum.

TAFT, M. (1994). Interactive-activation as a framework for understanding morphological processing. Language \& Cognitive Processes, 9 , 271-294.

TAFT, M., \& VAN GRANN, F. (1998). Lack of phonological mediation in a semantic categorization task. Journal of Memory \& Language, 38, 203-224.

Tan, L., Hoosain, R, \& Peng, D. (1995). Role of early presemantic phonological code in Chinese character identification. Journal of Experimental Psychology: Learning, Memory, \& Cognition, 2, 143-154.

Tzelgov, J., Henik, A., SNeg, R., \& BARUCH, O. (1996). Unintentional reading via phonological route: The Stroop effect with cross-scripthomophones. Journal of Experimental Psychology: Learning, Memory, \& Cognition, 22, 336-349.

VAN Orden, G. C. (1987). A ROWS is a ROSE: Spelling, sound, and reading. Memory \& Cognition, 15, 181-198.

Ziegler, J. C., Van Orden, G. C., \& JACobs, A. M. (1997). Phonology can help or hurt the perception of print. Journal of Experimental Psychology: Human Perception \& Performance, 23, 845-860.

\section{NOTES}

1. The DMASTR software synchronizes the display of an item to the video raster, and the display of a prime is in multiples of the screen refresh rate. Refreshing the screen in multiples of $14.2 \mathrm{msec}$ does not mean that the prime is displayed for $42.6 \mathrm{msec}$ but, rather, that it is refreshed three times over a period of $42.6 \mathrm{msec}$.

2. Shen and Forster (1999) speculated that priming in the naming task may be due to some special articulatory effect not generated for the lexical decision task. There are two reasons why this may not be the case. The first is that, recently, Kim and Davis (in press) demonstrated homophone priming with single character targets, where is seems unlikely that there was an articulatory priming effect (since there was no effect for primes that shared their first few phonemes with the targets). Second, there seems to be a more straightforward account of their pattern of data if it is assumed that the naming response is based on a phonological representation, whereas the lexical decision response is based on an orthographic one.

3. We specify orthographic from priming here because the task is to name written characters. For a character to activate a phonological representation, it must look like that word, since characters that sound like it will most likely look completely different.

(Manuscript received February 9, 1999; revision accepted for publication October 9, 2000.) 